\title{
Correction: Effect of Antihelminthic Treatment on Vaccine Immunogenicity to a Seasonal Influenza Vaccine in Primary School Children in Gabon: A Randomized Placebo- Controlled Trial
}

\author{
The PLOS Neglected Tropical Diseases Staff
}

There are errors in the Funding section. The correct funding information is as follows: The study was funded by the Bundesministerium für Bildung und Forschung (BMBF). The grant number is $01 \mathrm{KA} 1009$. The ministery can be found under the following url http://www.bmbf. de/.<http://www.bmbf.de/> (The author who received funding was ME.) The funders had no role in study design, data collection and analysis, decision to publish, or preparation of the manuscript." We acknowledge Deutsche Forschungsgemeinschaft and Open Access Publishing Fund of University of Tübingen for supporting publication costs.

\section{Reference}

1. Brückner S, Agnandji ST, Berberich S, Bache E, Fernandes JF, Schweiger B, et al. (2015) Effect of Antihelminthic Treatment on Vaccine Immunogenicity to a Seasonal Influenza Vaccine in Primary School Children in Gabon: A Randomized Placebo-Controlled Trial. PLoS Negl Trop Dis 9(6): e0003768. doi: 10.1371/journal.pntd.0003768 PMID: 26053679

\section{f OPEN ACCESS}

Citation: The PLOS Neglected Tropical Diseases Staff (2015) Correction: Effect of Antihelminthic Treatment on Vaccine Immunogenicity to a Seasonal Influenza Vaccine in Primary School Children in Gabon: A Randomized Placebo-Controlled Trial. PLoS Negl Trop Dis 9(6): e0003891. doi:10.1371/ journal.pntd.0003891

Published: June 24, 2015

Copyright: @ 2015 The PLOS Neglected Tropical Diseases Staff. This is an open access article distributed under the terms of the Creative Commons Attribution License, which permits unrestricted use, distribution, and reproduction in any medium, provided the original author and source are credited. 